\title{
The Spectacle of New Media: Addressing the Conceptual Nexus Between User Content and Valorization*
}

\author{
Raffaele Sciortino and Steve Wright
}

Capitalism is a system of relationships, which go from inside to out, from outside to in, from above to below, and from below to above. Everything is relative, everything is in chains. Capitalism is a condition both of the world and of the soul (Franz Kafka, in Janouch 1971, 151-2).

\section{Introduction}

The 1960s were years of massive social unrest and theoretical innovation. It is now a half century since that time which saw, amongst other things, the appearance of some key texts aimed at deciphering the nature of modern capitalist social relations. From the moment of their publication, Mario Tronti's Operai e capitale, and in a different way the French collection Lire le Capital, inspired many in their efforts to understand capital, and how best to undermine it. In terms of immediate and wide-reaching impact, however, pride of

How to cite this book chapter:

Sciortino, R. and Wright, S. 2017. The Spectacle of New Media: Addressing the Conceptual Nexus Between User Content and Valorisation. In: Briziarelli, M. and Armano, E. (eds.). The Spectacle 2.0: Reading Debord in the Context of Digital Capitalism. Pp. 81-94. London: University of Westminster Press. DOI: https://doi. org/10.16997/book11.e. License: CC-BY-NC-ND 4.0 
place amongst these pivotal works must be awarded to Guy Debord's The Society of the Spectacle, a book that was translated into nearly a dozen languages in the immediate aftermath of France's May '68 rebellion.

The Society of the Spectacle is a work that continues to fascinate, especially in today's Internet age. Nor does it seem a coincidence that, having been overshadowed by the defeat of the post-1968 wave of international struggles, Debord and his fellow Situationists were rediscovered precisely in the 1990s, a decade marked both by the collapse of the Soviet bloc, and the rise of the World Wide Web. While Debord himself died at the very moment that the Web began its ascent, his work has been cited by a range of commentators as a prescient account of a global capitalist order infused by online communication. As John Harris (2012) has argued:

when Debord writes about how 'behind the masks of total choice, different forms of the same alienation confront each other', I now think of social media, and the white noise of most online life. All told, the book is full of sentences that describe something simple, but profound: the way that just about everything that we consume - and, if we're not careful, most of what we do - embodies a mixture of distraction and reinforcement that serves to reproduce the mode of society and economy that has taken the idea of the spectacle to an almost surreal extreme.

Or as the former Situationist Timothy Clark (1998, x) once put it, 'the fact that Debord's imagining of other worlds shares so much with that of his opponents is potentially his imagining's strong point. It is what lets The Society of the Spectacle go on haunting the non-world of cyberspace.'

But things are not so cut and dried. It has rightly been pointed out that Debord does not simply conflate the spectacle with 'mass media'; instead, he seeks to draw attention to a system of social relations wherein 'direct experience and the determination of events by individuals themselves are replaced by a passive contemplation of images (which have, moreover, been chosen by other people)' (Jappe 1999, 6). Therefore, the spectacle is 'not a collection of images', but 'rather ... a social relationship between people, mediated by images' (Debord 1995, 12). In elaborating the mechanisms that permit the ongoing rule of capital in the modern world, Debord argues that 'the spectacle is a permanent opium war waged to make it impossible to distinguish goods from commodities, or true satisfaction from a survival that increases according to its own logic' (30). Viewed from this perspective, social media may well offer a critical instance within which to explore these complex border operations in the age of late capitalism. Crucially, this exploration turns on the question of the relationship online between production and consumption, between 'free activity' and capital's process of valorization and accumulation. 
Just as the spectacle entails more than 'mass media', so platforms such as Facebook entail more than mass media in the traditional sense that we have understood the term. According to one interpretation

Facebook offers promotional agencies the promise of a renewal, a reframed set of relations, interfaces, and engagements with consumers. Social media are key in ongoing efforts to enchant consumers, consumers serially identified as in flight from the abstractions and alienations of modern consumer society and the market, and from traditional advertising as the most visible signature of and locus of consumer modernity and 'promotional culture' ... The phenomenon and various experiences of and in Facebook are concurrently intensive and banal, creative and atrophying, as if being fed a minute-by-minute mailshot of Guy Debord's 'society of the spectacle' wrapped in an envelope of Michel de Certeau's 'everyday life' (MacRury 2013, 370-1).

In our view, the specificity of social media, within the broader context of today's 'network capitalism', lies in its ability to combine - economically, technologically, anthropologically - a new form of value appropriation through the free gift of users' activity, enacted (above all, if not exclusively) within the sphere of their own social reproduction. In reflecting upon the terms of the debate over how social media captures value, we will also explore the extent to which Debord's perspectives, as laid out in The Society of the Spectacle, continue to be useful for understanding what is new - and what on the contrary remains constant - within the process of capitalist accumulation.

\section{Some Preliminary Thoughts on Debord}

In presenting his understanding of the spectacle, Debord $(1995,15)$ seeks to address the meaning of capitalist domination in terms of totality. ${ }^{1}$ Seemingly all-encompassing in its domain, the spectacle 'covers the entire globe, basking in the perpetual warmth of its own glory'. As the second chapter of Debord's book spells out in some detail, the reign of the spectacle in turn 'corresponds' to the commodity form's 'colonisation of life': 'commodities are now all that there is to see; the world we see is the world of the commodity' (29). In one of the best introductions to Debord's work, Anselm Jappe (1999, 19-31) makes clear the debt here to History and Class Consciousness. In his classic 1923 text, Georg Lukács $(1971,10)$ asserts that the various specific components of society:

can really only be discerned in the context of the total historical process of their relation to society as a whole ... This dialectical conception of totality ... is the only method capable of understanding and reproducing reality. 
In a similar fashion, Debord holds that only by grasping the totality of capitalist social relations can the proletariat hope to destroy the latter. Both writers also agree that only one class has the possibility of grasping the totality, given that the proletarian condition underpins capitalist society as a whole. Echoing Marx, Debord $(1995,154)$ concludes The Society of the Spectacle by heralding the unique status of the proletariat as 'that class which is able to effect the dissolution of all classes', and thus the dissolution of class society itself.

Jappe $(1999,18)$ is correct in noting that 'the relevance of Debord's thought lies in his having been amongst the first to interpret the present situation in the light of the Marxian theory of value. Nonetheless, it is also striking how little attention Debord pays - at least in The Society of the Spectacle - to the processes through which that value is generated in the first place. Instead, his focus is upon the ways in which the life of all individuals has become subordinate to the commodity and its logic:

In all its specific manifestations - news or propaganda, advertising or the actual consumption of entertainment - the spectacle epitomises the prevailing model of social life. It is the omnipresent celebration of a choice already made in the sphere of production, and the consummate result of that choice ... [that] governs almost all time spent outside the production process itself. (Debord 1995, 13).

On the other hand, as the following discussion of explanations concerning the production and/or extraction of value in and around social media makes clear, assuming Debord's stance of totality carries the distinct advantage of raising fundamental questions about capitalist domination that might otherwise be all too easily overlooked. As we hope to show, there is a price to be paid if the circuit of value is read primarily through what we might call a 'Capital Volume 1' perspective, which interprets the activities of social media users as yet another moment in the immediate process of production. Doing so, we will argue, means overlooking that in order for capital to valourize itself, many human activities are necessary, not all of which take the form of wage labour. In this regard, to use the words of Jason W. Moore $(2014,38)$, 'value works only to the extent that most work is not valued. Grasping this means, therefore, taking up the perspective of totality championed by Debord, who in his own unique way chose to follow Marx (1981) in the critical exploration of 'The Process of Capitalist Production as a Whole.

Debord is explicit that the proletariat cannot be reduced to the waged (let alone productive workers) however they might be defined. ${ }^{2}$ More than this, the totalization of the commodity form has now rendered crucial the sphere of social reproduction, in all its articulations. What Marx once had presupposed as a relatively neutral given is today posited by capitalist production itself as intrinsic to its very concept. As the extension of commodity fetishism through the mediation of images comes to bedeck all access to 'reality', disconnecting 
subjects from their vital experience in the process, so the 'spectacle' encompasses the processes of social reproduction. The concrete phenomenology of this is evident all around us: the tendency to reduce experience to digitised images, within which it falls to networked computers to provide the 'social' dimension of life - a world seen rather than lived, in the sense of not being produced by subjects. This is a reality swallowed up by appearance, one wherein appearance becomes the only reality. So-called 'consumer society' thus corresponds to the total commodification of social life. In other words, it is the sphere of 'separate' human activity that the spectacle unifies, albeit as isolated moments: alienated production is overturned into a compensatory sociality through a 'controlled reintegration' (Debord 1995, 172) that revolves around exchange value as the new use value. Here the prospects of survival are increased, even as those of life itself are diminished.

\section{The Debate Around Value Production in Social Media and its Implications}

In the past decade, social media use has become a regular practice for hundreds of millions of individuals. Take Facebook, for example, a platform that can currently boast far more than one billion global 'active users' (Statista 2016). ${ }^{3}$ In turn, this level of engagement forms the basis of the corporation's enormous wealth. Back in early 2016, Fortune magazine reported that Facebook had surpassed Exxon to become the fourth most valuable firm in the world, while the personal wealth of Facebook CEO Mark Zuckerberg alone was estimated by Forbes in mid-2016 as nearly US\$55 billion (Zillman 2016; Forbes 2016).

If there is clearly more to social media than this particular firm, Facebook nonetheless offers a pertinent instance for considering the relationship between online platforms and valourization. As it stands, various explanations have been offered as to the source of this massive accumulation of capital over the past decade. For those committed in some way to developing the critique of political economy, debates concerning the basis of Facebook's power as a capital have been lively. In the process, quite different positions have been advanced. For example, according to Michel Bauwens (2012), Facebook creates a 'pooling of sharing and collaboration around their platform - and by enabling, framing and 'controlling' that activity, they create a pool of attention. It is this pool of attention which is sold to advertisers'. Assuming a somewhat different stance, Jakob Rigi and Robert Prey $(2015,396)$ nonetheless agree with Bauwens that it is as advertising-derived revenue that the source of the corporation's wealth can best be grasped: 'The money paid by advertisers to media is perhaps best understood as an exchange of rent for hope: the potential of generating greater future sales.'

In contrast, the most ambitious argument about the relationship between Facebook and value production has been advanced by Christian Fuchs, whose 
approach has the added advantage of seeking to grapple with the labouring performed by users at the site. In his 2014 book Digital Labour and Marx and elsewhere, Fuchs insists that there are a number of ways in which this activity is transformed into value for the firm: generating 'sociality' alongside 'data as commodity' that can be sold to advertisers, and in the process creating 'value in the form of online time, that is, labour time' (Fuchs 2014b, 4). Indeed:

The more time a user spends on Facebook, the more data is generated about him/her that is offered as a commodity to advertising clients. Exploitation happens in the commodification and production process (Fuchs 2014a, 276).

Fuchs concludes that because 'Facebook labour creates commodities and profits ... It is therefore productive labour' (263). At the same time, this is an unusual kind of productive labour, in that it is

unpaid work ... unpaid workers create more surplus value and profit than in a situation in which their labour would be conducted by regular labour that is paid. One hundred per cent of their labour time is surplus labour time, which allows capitalists to generate extra surplus value and extra profits (119).

In what is certainly his most distinctive line of argument, the merits or otherwise of which readers can determine for themselves, Fuchs (2015: 114) holds that:

the labour Facebook users perform enters the capital accumulation process of other companies in the realm of circulation, where commodities C' are transformed into money capital M' (C'- M'). Facebook users' labour is an online equivalent of transport work - their online activities help transporting use-value promises to themselves. Marx considered transport workers as productive circulation workers. Facebook users are productive online circulation workers who organise the communication of advertising ideologies on the Internet.

So far, we have examined these readings of social media's relation with accumulation in a way that is separated and juxtaposed, rather than one that is able to encompass the capital relation as a whole, including its subjective dimension. Assuming the latter standpoint, we would argue that readings such as Fuchs', for example, treat total capital as simply the sum of individual enterprises, with profit extraction determined at the level of the single firm. As a consequence, they tend to miss the qualitative leap in perspective made possible when matters are considered in terms of systemic reproduction, starting with the redistribution of surplus value amongst 'capitals' themselves (Caffentzis 1990). 
At the same time, readings that focus upon the mechanism of rent are able to approximate the heart of the matter, but tend to overlook both the peculiarities of the new forms of value appropriation in an online environment, and the human activities that underlie them (Sciortino 2016). Part of the problem is that this phenomenon is relatively new. More than this, the analytical recognition of the various dimensions involved (whether sociological, or cultural, or 'economic' in a strict sense), entails a given categorical reading of the value form, alongside a given way of reviewing the passage 'from the abstract to the concrete' within the different efforts to grasp the various but intertwined moments of capitalist totality.

Our thesis is that the specificity of social media, within the broader framework of networked capitalism, lies in combining - economically, technologically, anthropologically - a new form of appropriation of value from elsewhere (rent, with partly new characteristics) together with the free gift of users' gratuitous activity, carried out (above all, but not exclusively) within the sphere of their own social reproduction (Wright, Armano, Sciortino 2014). Without denying that this is a complex question, wherein different levels of capital's circuit are intertwined and often superimposed, we believe that analysis must not lose sight of the reality that the prevalent business model stems from advertising. As highlighted by a range of authors who likewise assume the perspective of total social reproduction (in particular, Robinson 2015, Frayssé 2015), advertising is based upon the transfer of value from other sectors of capital. More precisely, it is based on a part of surplus value originally produced by industrial capital and turned over, as the faux frais of production, to commercial circuits, which then transfer it in turn, under the guise of rent, to the owners of social media platforms.

It is not our intention in this chapter to offer any sustained argument in support of the thesis outlined above. Instead, we wish to subject some heuristic hypotheses to critical discussion, by drawing attention to a series of nodes implicit in our approach. Having said that, it would certainly be useful to develop our thesis further, preferably in the form of a (necessarily collective) militant enquiry - although what that might mean in the context of Debord's 'society of the spectacle' is itself worthy of discussion. For now, we offer three avenues for future exploration.

In the first place, the transfer of value to proprietary social media, primarily through the commercial capital of advertising agencies, is a process made possible by two general conditions. On the one hand, we have the Internet as the organization and intertwining of digital computers, through which operates a peculiar form of automation. This is what Zuboff (1988) called 'informating', a process that not only tallies the data generated through past actions and transactions but, thanks to the recursive nature of algorithms, transforms such data into information that can support the decision making of those who control social media platforms. It is this that permits, amongst other things, the profiling of users' metadata, and therefore the provision of targeted advertising 
spaces. On the other hand, the supply of new enclosed Internet spaces is based on the attraction of users to free services that facilitate the formation of online social communities. It is this expropriation of free gifts exchanged online between users that makes it possible to suck in value from other capitalist sectors in the form of rent. At this point we can note, in passing, how Debord was able to anticipate, starting from an analysis of the totalisation of the capitalist social relation, the tendency towards a particular form of sociality. This is a sociality aimed at integrating within the system individuals who are 'isolated together': 'the generalized use of receivers of the spectacle's messages ensures that his isolation is filled with the dominant images - images that indeed attain their full force only by virtue of this isolation' (Debord 1995, 122). Here, then, is a potential that 'only' awaits its adequate technology: further proof, against any kind of technological determinism, that social relations prepare the conditions required for technological development, rather than vice versa.

The peculiarity of this enclosure, and the activity of online users bound up with it, are the elements that most demand closer scrutiny. While these have drawn far less attention from most of those who support the 'rent' thesis (and probably deem it 'extra-economic'), they have instead caught the eye of two groups:

a) some Capital Volume 1-style 'workerists' (who at least have the merit of addressing the activity of users, even if they equate the latter too readily with productive labour);

b) those 'post-workerists' who read it as 'free labour', tossing it into the indeterminate cauldron of the multitude's cooperation, which is presumably generated in turn autonomously from capital. ${ }^{4}$

It is precisely on this terrain that the question becomes evident of the evergreater entwining of capital's total circuit with the 'circuit' of the proletariat's reproduction, and its consequences for the constitution of the latter's subjectivity. There are a number of reasons why users can themselves be 'used' by proprietary social media platforms. To start with, those human activities that are bound up with social reproduction - of which online sociality is one form, together with care work, education, and other pursuits - have for a long time been subordinated to processes of 'labourfication. ${ }^{5}$ This term refers to the tendency to 'industrialize' such activities by rendering them, in the concrete forms through which they are distributed and organised, analogous to industrial labour (which in turn, as is known, has been notably transformed by processes of digitization, flexibilization etc.), whilst extinguishing their 'artisanal' forms of conception, formation and execution. On the other hand, and as a consequence of this, they can be subordinated to processes that subsume them to 'tele-combined', networked machinery - that is, to the digital codification of vital experience and to algorithmic mechanisms, as every activity of consumption in a broad sense tends towards subsumption. In this aspect too, 
the spectacle as understood in Debord's sense has been enormously magnified. Nor does the process seems to be anywhere near completion, although this by no means necessarily entails the immediate equation of all such 'labourfied' reproductive activities with labour that is directly productive of value, or of their products/services with commodities containing value. ${ }^{6}$ What the process of 'labourfication' does do, however, is to throw new light on the classic question of the relation between the formal and real subsumption of labour under capital, extending this to reproductive activities, even as various digital means act to blur any clear distinction between direct and indirect control on the part of capital.

In the second place, reference to Marx's theory of rent, being grounded in a reading of capital's reproduction as a whole, is fundamental for interpreting accumulation processes within social media. At the same time, it is also true that this type of rent, far from following familiar and established forms, presents new aspects that demand further scrutiny. In effect, we find ourselves before second-order enclosures that are already human, social constructions, woven together with infrastructural capital and subjected to ongoing technological innovation. In such circumstances, the 'space' offered by advertising as a source of rent needs to catch the attention of a human brain that is inserted in an environment combined with computers and other means fully subsumed to capital. Here it is worth recognizing that proprietary social media themselves make capital investments with the aim not of 'production', but rather of establishing an enclosure from which rent can be drawn. This occurs, on the one hand, through the largely free appropriation of the products of highly qualified 'general' cognitive labour, that develops algorithms and software. While being privatized (that is, appropriated by capitalist enterprises), this labour does not stand in relation to abstract labour time, which means that rather than produce value, it becomes a free gift for capital that in turn permits new enclosures (Verzola 2004; Lohoff 2007). On the other hand, the 'maintenance' labour provided by waged knowledge workers, whose programs process metadata automatically generated by users' activities, allows social media platforms like Facebook to reduce their costs, as well as to better target prospective markets for individual advertisers. In any case, the fundamental novelty here lies in the spaces for rent generation that are nurtured by the peculiar reproductive activities of users: activities that are more than mere survival, as attested in a contradictory way both by the level reached today by what Marx once called 'the social individual', and by the latter's subsumption to the 'spectacle'.

A third node concerns the intimate relationship between the high concentrations of media-based capital online, and the incredible stock market valuations of the leading social media companies. While we lack the space here to address this question at length, it is clear that this matter cannot be critically addressed without recourse to Marx's category of 'fictitious capital' (Goldner 2012). According to the more considered Marxist readings of this phenomenon, 'fictituous capital' is not some 'speculative' outgrowth, but instead the 
new norm of capitalist accumulation in a phase more commonly defined as 'neoliberal', closely linked not only to the intermeshing of stock markets and central banks (like the US Federal Reserve), but also to geopolitical dynamics (as evidenced, for example, by the cooperation displayed in the Middle East and elsewhere between social media and the soft power of US imperialism). From this point of view, it becomes impossible to separate the 'parasitic' aspect of rent by counterposing it to the presumably 'healthy' dimension of productive labour and profit.

In conclusion, a critical analysis of social media confirms that reading capital as a fetishized class relation makes it possible to thematize both capital's systemic reproduction and the social reproduction of the proletariat. This is so not simply in the way that the two converge (the subsumption not just of the commodity labour power, but the tendency to subsume all activities to capital, without necessarily reducing them all to productive wage labour), but also in the way in which, by doing so, terrains of contradictions and potential antagonisms are constituted. Our interpretation of Debord hopes to offer a reading that challenges the appearance of an 'integrated spectacle' that holds sway over us all. It does this by understanding that not every commodity has a value, that not every human activity necessary for capitalist accumulation can be reduced to productive labour, ${ }^{7}$ and that capital is impelled to reduce socially necessary labour time to a minimum (while persisting and even magnifying itself as measure of wealth). All of this indicates that production based upon value and capital has determinant limits, and that paradoxically these limits increase to the extent that the 'spectacle' is amplified and intensified - without in the last instance expanding accumulation, other than in ways that are transitory and 'fictitious' (if no less real for all that). In this way, it may be worthwhile to return our critical attention to a range of themes expressed by the most interesting and radical currents of the 1960s and 1970s (spectacle, total capital, social factory, socialized worker), while avoiding any false antithesis between the 'iron cage' of a totalized wage relation at one extreme, or the idea of a proletariat that is already fully autonomous 'for itself' at the other.

\section{Notes Towards a Conclusion. Against Impotence: Promises and Limits}

Certainly, we do not wish to overlook the weaker aspects of Debord's analysis. Amongst other things, his work betrays a certain 'young-Hegelianism' that, much like the 'young' Lukács, too neatly counterposes subject/object and production/passivity. The most problematic features of Debord's critique, however, lie in his dependence upon the categories of class consciousness and false consciousness (which, moreover, are overwhelmed by the processes of the spectacle), along with his undervaluing of any possible self-activation of subjects even within a fetishized world. And while Debord himself was obviously never able 
to confront the matter, we also need to consider the implications for his analysis that are raised by the various transformations currently under way on the front of production. Nonetheless, in Debord the constitution of subjectivity as subordinate but also potentially antagonistic, is thematized at the overall level of the social relations of production and reproduction of life under capital, well beyond every factoryist reductionism (something that was widespread in the 1960s, for example within operaismo), beyond the merely additive logic of cultural studies, and also against readings à la Foucault in which forms of submission are separated from the trajectory of the value form and the struggle against the latter. Furthermore, in emphasizing the importance of the ambit of social (albeit 'spectacularized') reproduction as the other side of a fragmented and alienated sphere of production, Debord poses, at the centre of humanity's challenges, the node of constructing activities that are immediately social ('a mass of new practices ... are seeking their theory' - Internationale Situationniste 1963, 10). Last but not least, the proletariat, understood in a broad sense, remains the potential dissolution of social separation (the task determines the figure/subject), a dissolution that can only occur simultaneously in both the spheres of production and social reproduction (which are in any case increasingly enmeshed). ${ }^{8}$ Since this process entails the decomposition of the old type of class society, moments of dissolution and of reconstruction will likewise be inextricably entwined in the revolutions to come.

\section{Notes}

* We would like to thank the editors, Christian Fuchs, and an unidentified reviewer for their comments on an earlier version of this chapter.

${ }^{1}$ It would be worthwhile, on another occasion, to critically assess Debord's reading of totality in light of the work of Camatte (1988).

2 See also Dyer-Witheford 2015.

3 Statista 2016 - http://www.statista.com/statistics/264810/number-ofmonthly-active-facebook-users-worldwide/, which defines active users as 'those which have logged in to Facebook during the last 30 days'.

${ }^{4}$ It would be useful to compare these positions, both of which commonly find inspiration in Negri's 1970s thesis of the operazio sociale, with debates from that decade concerning money and class composition, given that this was the moment when the majority - but not all - operaisti chose to abandon the analytical link between value, production and measure (Wright 2013). It would be equally useful to explore the extent to which this abandonment (touched upon, but not discussed at length, in Wright 2002) helped to determine the subsequent flaws that lie at the heart of so much of postworkerist analysis (Formenti 2011; Wright 2009).

${ }^{5}$ For these concepts, see Alquati $(1989,2000)$. In the 1960s, Romano Alquati was one of the chief theorists and researchers within Italian workerism. 
Creator of 'militant co-research' and the concept of class composition, Alquati went beyond that approach, identifying the passage to a new capitalist phase that from the 1980s onwards he analysed as a 'hyper-industrial society', characterised by the extension - through the involvement of the cognitive dimensions of human activity combined with new forms of fixed capital - of processes of industrialisation within the activities of social reproduction. An anthology of his writings will be published in 2017 or thereabouts by Verso Press. If nothing else, Alquati's work suggests that so-called Italian autonomist Marxism is more nuanced and complex than might otherwise be thought based on what has been translated into English to date.

${ }^{6}$ Obviously this does not mean that reproductive activities cannot be reduced to wage labour if they are exchanged with capital (as in fact already occurs for various types of caring and education-related labour) and as such are organised within an enterprise (in Marx's sense: an independent private producer whose product is not immediately social, but becomes such if and only if it is exchanged on the market and realises its 'value'). Against this, users of social media directly exchange social experiences without for now objectifying these first as a commodity - even if, on the other hand, this takes place in an increasingly 'industrialized' environment that could certainly be the prelude to their complete subsumption under capital.

${ }^{7}$ Far from arguing that only labour that is productive in a capitalist sense is important for both accumulation and the struggle against it, Marx (1976, 644) reminds us that 'To be a productive worker is therefore not a piece of luck, but a misfortune'.

${ }^{8}$ Along with Jarrett (2015), an excellent collection of recent reflections concerning social reproduction can be found at Viewpoint Magazine (2015).

\section{References}

Alquati, Romano. 1989. Dispense di sociologia industriale. Turin: Il Segnalibro. Alquati, Romano. 2000. Nella società industriale d’oggi. Unpublished manuscript.

Bauwens, Michel. 2012. 'The $\$ 100$ bn Facebook question: Will capitalism survive 'value abundance'?', Aljazeera, 29 February. http://www.aljazeera.com/ indepth/opinion/2012/02/20122277438762233.html

Caffentzis, George. 1990. 'Africa and Self-reproducing Automata', in The New Enclosures, ed. Midnight Notes. New York: Autonomedia: 35-41.

Camatte, Jacques. 1988. Capital and Community. London: Unpopular Books.

Clark, Timothy. 1998. 'Foreword' to Anselm Jappe, Guy Debord. Berkeley: University of California Press.

Debord, Guy. 1995. The Society of the Spectacle, translated by Donald Nicholson-Smith. New York: Zone Books. 
Dyer-Witheford, Nick. 2015. Cyber-Proletariat. London: Pluto.

Forbes. 2016. 'Mark Zuckerberg', Forbes. http://www.forbes.com/profile/markzuckerberg/

Formenti, Carlo. 2011. Felici e sfruttati. Capitalismo digitale e eclissi del lavoro. Milano: Egea.

Frayssé. Olivier. 2015. 'Is the Concept of Rent Relevant to a Discussion of Surplus Value in the Digital World?', in Reconsidering Value and Labour in the Digital Age. New York: Palgrave Macmillan, eds. Eran Fisher and Christian Fuchs: $172-187$.

Fuchs, Christian. 2014a. Digital Labour and Karl Marx. New York: Routledge.

Fuchs, Christian. 2014b. 'Against Divisiveness', Television \& New Media, online pre-print: $1-10$.

Fuchs, Christian. 2015. Culture and Economy in the Age of Social Media. New York: Routledge.

Goldner, Loren. 2012. 'Fictitious Capital and Contracted Social Reproduction Today'. http://breaktheirhaughtypower.org/fictitious-capital-and-contractedsocial-reproduction-today-china-and-permanent-revolution/

Harris, John. 2012. 'Guy Debord predicted our distracted society'. The Guardian, 30 March. https://www.theguardian.com/commentisfree/2012/mar/30/guydebord-society-spectacle

Internationale Situationniste. 1963. 'Ideologies, Classes and the Domination of Nature', Internationale Situationniste 8, January, translated by Ken Knabb. http://www.cddc.vt.edu/sionline/si/ideologies.html

Janouch, Gustav. 1971. Conversations with Kafka. 2nd edition, translated by Goronwy Rees. London: Andre Deutsch.

Jappe, Anselm. 1999. Guy Debord. Berkeley: University of California Press.

Jarrett, Kylie. 2015. 'Devaluing Binaries: Marxist Feminism and the Value of Consumer Labour', in Reconsidering Value and Labour in the Digital Age. New York: Palgrave Macmillan, eds. Eran Fisher and Christian Fuchs: 207-223.

Lohoff, Ernst. 2007. 'Der Wert des Wissens. Grundlagen einer Politischen Ökonomie des Informationskapitalismus', Krisis 31. http://www.krisis. org/2007/der-wert-des-wissens/

MacRury, Iain. 2013. 'Back to the Future. Gifts, Friendship, and the Re-figuration of Advertising Space', in The Routledge Companion to Advertising and Promotional Culture. New York: Routledge, eds. Matthew McAllister and Emily West: 357-372.

Marx, Karl. 1976. Capital. Volume 1. Harmondsworth: Penguin.

Marx, Karl. 1981. Capital. Volume 3. Harmondsworth: Penguin.

Moore, Jason. 2014. The Capitalocene Part II: Abstract Social Nature and the Limits to Capital. Working Paper, Fernand Braudel Center and Department of Sociology Binghamton University.

Rigi, Jakob \& Robert Prey. 2015. 'Value, Rent, and the Political Economy of Social Media', The Information Society, 31 (5): 392-406. 
Robinson, Bruce. 2015. 'With a Different Marx: Value and the Contradictions of Web 2.0 Capitalism', The Information Society, 31 (5): 44-51.

Sciortino, Raffaele. 2016. 'Tutto un programma di ricerca', in Le reti del lavoro gratuito. Padova: Ombre Corte, ed. Emiliana Armano and Annalisa Murgia: 114-120.

Terranova, Tiziana. 2000. 'Free Labor: Producing Culture for the Digital Economy', Social Text 63, Summer: 33-58.

Verzola, Roberto. (2004) Towards a Political Economy of Information. Quezon City: Foundation for Nationalist Studies.

Viewpoint Magazine 2015. 'Issue 5: Social Reproduction', Viewpoint Magazine. https://viewpointmag.com/2015/11/02/issue-5-social-reproduction/

Wright, Steve. 2002. Storming Heaven: Class Composition and Struggle in Italian Autonomist Marxism. London: Pluto.

Wright, Steve. 2009. 'Reality check: Are we living in an immaterial world?', in Proud to be Flesh: A Mute Magazine Anthology of Cultural Politics after the Net, ed. Josephine Berry Slater, Pauline van Mourik Broekman, Michael Corris, Benedict Seymour, Anthony Iles and Simon Worthington: 472-80. London: Mute.

Wright, Steve. 2013. 'Revolution from Above? Money and Class-Composition in Italian Operaismo', in Beyond Marx: Theorising the Global Labour Relations of the Twenty-First Century, ed. Marcel van der Linden and Karl Heinz Roth: 369-94. Leiden: Brill.

Wright, Steve, Emiliana Armano and Raffaele Sciortino. 2014. 'Facebook as a value-producing machine on the net? Interpretative hypotheses and traces of a phenomenology', Paper presented at University of Hertfordshire Conference, The Dynamics of Virtual Work.

Zillman, Claire. 2016. 'Facebook is now more valuable than Exxon', Fortune 1 February. http://fortune.com/2016/02/01/facebook-value-exxon/

Zuboff, Shoshanna 1988. In the Age of the Smart Machine. New York: Basic Books. 